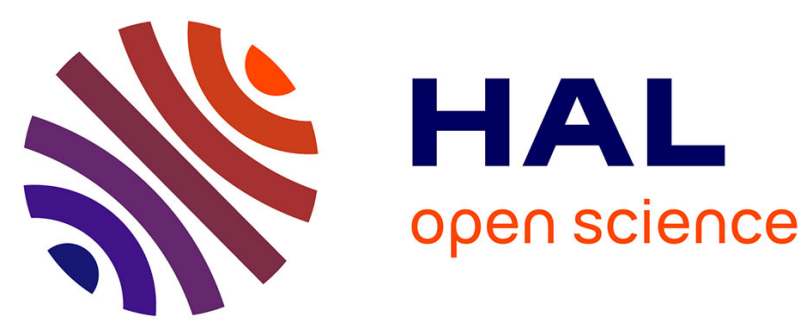

\title{
Transcriptome classification of $\mathrm{HCC}$ is related to gene alterations and to new therapeutic targets.
}

Sandrine Boyault, David S. Rickman, Aurélien de Reyniès, Charles Balabaud, Sandra Rebouissou, Emmanuelle Jeannot, Aurélie Hérault, Jean Saric, Jacques Belghiti, Dominique Franco, et al.

\section{To cite this version:}

Sandrine Boyault, David S. Rickman, Aurélien de Reyniès, Charles Balabaud, Sandra Rebouissou, et al.. Transcriptome classification of HCC is related to gene alterations and to new therapeutic targets.: Transcriptome and HCC classification. Hepatology, 2007, 45 (1), pp.42-52. 10.1002/hep.21467 . inserm-00130313

\section{HAL Id: inserm-00130313 https://www.hal.inserm.fr/inserm-00130313}

Submitted on 3 Nov 2009

HAL is a multi-disciplinary open access archive for the deposit and dissemination of scientific research documents, whether they are published or not. The documents may come from teaching and research institutions in France or abroad, or from public or private research centers.
L'archive ouverte pluridisciplinaire HAL, est destinée au dépôt et à la diffusion de documents scientifiques de niveau recherche, publiés ou non, émanant des établissements d'enseignement et de recherche français ou étrangers, des laboratoires publics ou privés. 


\section{Transcriptome classification of $\mathrm{HCC}$ is related to gene alterations and to new therapeutic targets}

Sandrine Boyault ${ }^{1,2 *}$, David S. Rickman ${ }^{3 *}$, Aurélien de Reyniès ${ }^{3 *}$, Charles Balabaud ${ }^{4,5}$, Sandra Rebouissou ${ }^{1,2}$, Emmanuelle Jeannot ${ }^{1,2}$, Aurélie Hérault ${ }^{1,2}$, Jean Saric ${ }^{6}$, Jacques Belghiti ${ }^{8}$, Dominique Franco ${ }^{9}$, Paulette Bioulac-Sage ${ }^{4,7}$, Pierre Laurent-Puig ${ }^{10}$, Jessica Zucman-Rossi ${ }^{1,2 * *}$

${ }^{1}$ Inserm, U674; CEPH-Fondation Jean Dausset, Paris France;

${ }^{2}$ Université Paris 7, IUH, Saint-Louis, Paris, France;

${ }^{3}$ Bioinformatic department; Ligue nationale contre le cancer; LNCC, Paris, France;

${ }^{4}$ Inserm, E0362; GREF; Université Bordeaux 2, CHU Bordeaux, France;

Departments of ${ }^{5}$ Hepatology, ${ }^{6}$ Surgery, and ${ }^{7}$ Pathology, Centre Hospitalier Universitaire de Bordeaux, France;

${ }^{8}$ AP-HP, Surgery department, hôpital Beaujon, Clichy, France;

${ }^{9}$ AP-HP, Surgery department, Hôpital Antoine Béclère, Clarmart, France;

${ }^{10}$ Inserm, U775; Université Paris 5, France;

*Equally contributed to this work

**Corresponding author: Inserm U674, CEPH-Fondation Jean Dausset, IUH-Saint-Louis, 27 rue Juliette Dodu, 75010 Paris, France. TEL: 331537251 66. FAX: 331537251 58. Email: zucman@,cephb.fr

Short title: trancriptome and HCC classification

Key Words: tumor suppressor gene; microarray; ß-catenin; AKT pathway; HBV 


\begin{abstract}
Hepatocellular carcinomas (HCC) are a heterogeneous group of tumors that differ by risk factors and genetic alterations. We have further investigated transcriptome-genotype-phenotype correlations in HCC. Global transcriptome analyses were performed on $57 \mathrm{HCC}$ and 3 hepatocellular adenomas and validated by quantitative RT-PCR using 63 additional HCC. We determined losses of heterozygosity, gene mutations, promoter methylation of $C D H 1$ and $C D K N 2 A$, and HBV DNA copy number for each tumors. Unsupervised transcriptome analysis identified six robust subgroups of $\mathrm{HCC}$ (G1 to G6) associated with clinical and genetic characteristics. G1-tumors were associated with HBV low copy number and over-expression of genes expressed in fetal liver and controlled by parental imprinting. G2 included HCCs infected with a high copy number of HBV and mutations in PIK3CA and TP53. In these first groups, we detected a specific activation of the AKT pathway. G3-tumors were typified by a mutation of TP53 and an over-expression of genes controlling the cell-cycle. G4 was a heterogeneous subgroup of tumors including TCF1 mutated hepatocellular adenomas and carcinomas. G5 and G6 were strongly related to $\beta$-catenin mutations leading to Wnt pathway activation; and in particular G6-tumors were characterized by satellite nodules, higher activation of the Wnt pathway and E-cadherin under-expression. These results have furthered our understanding of the genetic diversity of human $\mathrm{HCC}$ and have provided specific identifiers to classify tumors. In addition, our classification has potential therapeutic implications since $50 \%$ of the tumors were related to WNT or AKT pathways activation, potentially targeted by specific inhibiting therapies.
\end{abstract}

Words Count: 246 
Hepatocellular carcinoma (HCC) is one of the most frequent solid tumors worldwide and represents the third cause of mortality among deaths from cancer(1). Liver cirrhosis of any origin and dysplastic regenerative nodules have long been considered to be the likely precursors of HCC because of their frequent association with the HCC occurrence(2, 3). As in other solid tumors, a large number of genetic alterations accumulate during the carcinogenetic process. Some of these genetic alterations are specific to HCC etiological risk factors, particularly HBV infection which can induce chromosome instability or insertional mutagenesis(4). Among the genetic alterations unrelated to $\mathrm{HCC}$ risk factors, microsatellite allelotypes and comparative genomic hybridization (CGH) studies have demonstrated recurrent chromosome aberrations(5). Altogether, the principal carcinogenetic pathways known to be deregulated in HCC are the inactivation of TP53(6), Wnt/wingless activation mainly through CTNNB1 mutations activating B-catenin and $A X I N 1$ inactivating mutations(7-9), retinoblastoma inactivation through $R B 1$ and $C D K N 2 A$ promoter methylation and rare gene mutations $(10,11)$, insulin growth factor activation through $I G F 2$ over-expression and $I G F 2 R$ inactivating mutations $(12,13)$.

We have previously shown that genetic alterations are indeed closely associated with clinical characteristics of HCC defining two mechanisms of hepatocarcinogenesis(14). The first type of HCC was associated with not only a high level of chromosome instability, frequent TP53 and AXIN1 mutations but also closely linked to HBV infection and a bad prognosis. Conversely, the second subgroup of HCC tumors was chromosome-stable, having a high incidence of activating $\beta$-catenin alterations and was not associated with viral infection. To further investigate genotype-phenotype correlations in $\mathrm{HCC}$, identify pathways and/or biological processes deregulated in such heterogeneous tumors, we performed a comprehensive analysis at the clinical, genetic and transcriptomic level in $57 \mathrm{HCC}$ and 3 adenomas and we validated the results using quantitative RT-PCR in 63 new independent HCCs. 


\section{$\underline{\text { Patients and methods }}$}

\section{Tumor samples and clinical data}

A series of $120 \mathrm{HCC}$ and 3 hepatocellular adenomas were collected from 123 patients surgically treated in 3 French surgical departments from 1992 to 1999. A first group of tumors (57 HCC and 3 hepatocellular adenomas) was used for genome-wide transcriptome microarray analysis and a second group of 63 independent HCCs was used for validation by quantitative RT-PCR analysis. All these tumors were clinically characterized as previously described(14) (supplementary table 1). Briefly, the entire series of patients consisted of the following: 4:1 (M:F) gender ratio, 79\% were born in France, mean age was 60. Risk factors for HCC of hepatitis B virus, hepatitis C virus, alcohol abuse, and hemochromatosis occurred in 30\%, 25\%, $33 \%$ and 5\%, respectively. HCCs developed from cirrhotic liver or severe chronic hepatitis disease in $68 \%$ of the cases. The histological grade of tumor differentiation was assigned according to the Edmondson and Steiner grading system, grade I (7\%), II (49\%), III (39\%) and IV (4\%). Tumor size ranged from 3 to $190 \mathrm{~mm}($ median $=60 \mathrm{~mm})$. In 103 cases the preoperative $\alpha$-fetoprotein serum level was available and over $100 \mathrm{IU} / \mathrm{ml}$ for 37 patients. Macroscopic and/or

microscopic vascular invasion was recorded in 38\% of the cases. Satellite tumors defined by nodule(s) found at less than $1 \mathrm{~cm}$ from the main tumor was recorded in $42 \%$ of the cases. For the Affymetrix analysis, 5 pools of 3 non-tumor liver tissues matching the analyzed tumors were used including alcoholic cirrhosis (pool 1), alcoholic non-cirrhotic liver (pool 2), HBV noncirrhotic liver (pool 3), HCV cirrhosis (pool 4) and HBV cirrhosis (pool 5). In the QRT-PCR experiments, we analyzed these 15 non-tumor RNAs and 6 additional normal non-tumor liver RNAs. We used 19 human fetal liver samples at different stages of development (ranging from 11 to 29 weeks of pregnancy) to test for genes potentially expressed during fetal life using QRTPCR. The study was approved by the local Ethics Committee (CCPPRB Paris Saint-Louis), and informed consent was obtained in accordance with French legislation.

\section{Gene mutations, chromosome imbalance, quantification of HBV genome and DNA methylation}

For each tumor, we screened for gene mutations in TP53, CTNNB1 coding for ß-catenin, AXIN1, PIK3CA, EGFR, KRAS, NRAS and HRAS using direct sequencing. Primers and protocols are available upon request and all mutations are described in supplementary Table $\mathbf{2}$. Genome-wide 
allelic losses were assessed as previously described(14). For all samples related to HBV infection either by serological results or viral DNA amplification, $H B S$ and $H B X$ copies of DNA were quantified in tumor and non-tumor DNAs using the Syber Green method (Applied Biosystems), for further details, see supplementary materials and methods. DNA methylation at $C D H 1$ and $C D K N 2 A$ promoter was assessed for using bisulfite DNA and methylation specific amplification as previously described $(15,16)$.

\section{Gene expression analysis}

Microarray analyses for $57 \mathrm{HCC}, 3$ hepatocellular adenomas and 5 pools of non-tumor samples were performed using $5 \mu \mathrm{g}$ of total RNA and $20 \mu \mathrm{g}$ cRNA per hybridization (GeneChip Fluidics Station 400) of HG-U133A Affymetrix GeneChip ${ }^{\mathrm{TM}}$ arrays and analyzed following the manufacturer's protocols. All methodological details of the gene expression analysis are given in supplementary materials and methods.

\section{Quantitative RT-PCR data processing}

Quantitative RT-PCR was performed in duplicate, using TaqMan ${ }^{\circledR}$ Low Density Array and the ABI PRISM® 7900HT System (Applied Biosystems) for 109 HCCs (46 among the "microarray" series of $57 \mathrm{HCCs}$, and 63 new samples) and 21 non-tumor liver samples. Briefly, expression results of a gene were normalized to internal control ribosomal $18 \mathrm{~S}$ and relative to the mean expression level of the corresponding gene in non-tumor samples normalized to internal control ribosomal 18S.

\section{Western blot and immunohistochemistry}

Frozen tissues were homogenized in RIPA Lysis buffer (Santa Cruz) and protein concentration was determined by BCA protein assay kit (Pierce). Immunoblot analysis was performed using antibodies E-cadherin (SC-7870, 1:500, Santa Cruz), AKT (\#9272, 1:2000, Cell Signalling), Phospho-AKT ser473 (\#9271, 1:200, Cell Signalling), Phospho-GSK3 ser9 (\#9336, 1:500, Cell Signalling), IGF1Rß (\#3027, 1:500, Cell Signalling), peroxidase-conjugated secondary antibody (1:2000, Santa Cruz) and enhanced chemoluminescence (ECL, Pierce). Immunostaining was performed using monoclonal anti-ß3-catenin as previously described(17). 


\section{Results:}

\section{Unsupervised transcriptome analysis defines clusters of tumors closely associated with clinical data and genetic alterations}

In the whole series of 123 tumors (120 HCC and 3 hepatocellular adenomas) we identified mutations in CTNNB1 (encoding ß-catenin), TP53, AXIN1, TCF1, PIK3CA, KRAS gene in 34, 31, 13, 5, 2 and 1 cases, respectively (supplementary Table 2). No mutations were found in $N R A S, H R A S$ and EGFR. Hypermethylation of the CDKN2A and $C D H 1$ promoter were identified in $35 \%$ and $16 \%$ of the cases, respectively.

Fifty-seven HCC, 3 hepatocellular adenomas and 5 samples of pooled non-tumor tissues were analyzed using Affymetrix HG-U133A GeneChip ${ }^{\mathrm{TM}}$ arrays. Based on a hierarchical clustering analysis using the 6,712 probe sets whose expression vary the most across samples, we classified tumors into 2 major groups each being further divided into 3 smaller subgroups (G1 to G6, Figure 1). This classification was found to be extremely robust (mean reproducibility score was found to be at least $90 \%$ for the 2 major groups and the 6 subgroups), and was conserved across different gene lists and clustering methods.

We observed a high level of association between this HCC classification and genetic alterations and clinical factors (Table 1). The tumors in groups G1 to G3 are associated with high level of chromosome instability yielding a significantly higher fractional allelic loss (FAL) compared to the tumors in groups G4 to G6 $\left(P<10^{-2}\right)$. Among the frequent somatic gene mutations observed, the G5-G6 subgroups were highly associated with CTNNB1 mutations $\left(P<10^{-10}\right)$ and the G2-G3 subgroups with TP53 mutations $(P=0.03)$. The rare TCF1 and $P I K 3 C A$ mutations were associated with $\mathrm{G} 4$ subgroup $(P=0.01)$ and $\mathrm{G} 2$ subgroup $(P=0.01)$, respectively. Hypermethylation of E-cadherin $(C D H 1)$ and $\mathrm{P} 16(C D K N 2 A)$ gene promoter were most frequently observed in G5-G6 and G3 subgroups, respectively. In addition, HCC related to HBV infection were found in groups G1 to G3 and more specifically, tumors with low number of HBV DNA copies were related to G1 subgroup $\left(P<10^{-4}\right)$. We validated these associations based on the classification of a second set of 63 independent tumors using quantitative RT-PCR. 


\section{Identification of a predictor of the 6-groups classification}

To more easily classify tumors, we sought to define a gene-predictor that would use quantitative RT-PCR data (for details see supplementary material and method, supplementary Table 3). We identified a combination of 16 genes (Figure 2) that correctly classified 45 out of 46 HCC previously characterized in Affymetrix experiment. We then used this signature to partition the validation series of 63 independent HCC samples into 6 subgroups. As observed in the first set of tumors analyzed in Affymetrix experiment, significant associations were found between genetic alterations and the different predicted subgroups ( $\underline{\text { Table 1) }}$. These associations were confirmed using the complete series of $120 \mathrm{HCC}$ tumors either classified using both Affymetrix and QRT-PCR ( $\mathrm{n}=46)$, Affymetrix only $(\mathrm{n}=11)$ or QRT-PCR only $(\mathrm{n}=63)$ (Table 1 and Figure 3). We further searched to identify deregulated pathways in each groups of tumors.

\section{Identification of key signaling pathways implicated in HCC subgroups}

The HCC groups G1 to G3 (associated with a high rate of chromosome instability) were enriched with an over-expression of cell cycle/proliferation/DNA metabolism genes $(P<0.01$, see supplementary Table 4 and 5 ).

\section{a- Parentally imprinting genes were over-expressed in HCC subgroup G1}

Among the high number of genes specifically over-expressed in the G1 subgroup (HBV infection with a low number of viral DNA, AXIN1 mutations, a younger age, a high sera level of AFP and frequent origin from Africa (Figure 3, Table 1 and supplementary Table 4) we found genes encoding proteins expressed during development: myosin heavy chain IIb, MYH4, the transcription factor $S O X 9$, and parentally imprinted genes: insulin like growth factor 2 (IGF2), paternally expressed gene 3 and 10 (PEG3 and $P E G 10)$, alpha-fetoprotein $(A F P$ ) and sarcoglycan epsilon $(S G C E)$. The differential expression of all these genes was validated using QRT-PCR on 109 HCC tumors (Figure 4a). The parentally imprinted genes were highly overexpressed in normal fetal livers. H19 mRNA was also over-expressed, not only in G1 samples but also in fetal samples, correlating with the level of IGF2 mRNA expression in these two groups $\left(\mathrm{R}^{2}=0.4\right.$ and 0.6 , respectively). Interestingly, in the non-supervised classification, the 
mRNA level of expression of AFP was identified as a discriminating marker of the G1 tumors and correlation with a high AFP sera level was observed (Table 1 and Figure 3 ).

\section{b- HCC tumors in subgroup G2 included the rare PIK3CA mutated cases}

Subgroup G2 tumors was related to HBV infection with a high number of viral DNA copies, frequent local and vascular invasion and TP53 mutations (Table 1 and Figure 3). An association with hemochromatosis related tumors was only observed in the validation set may be due to the overall small number of tested patients $(n=6$, Table 1). Interestingly, in the whole series we identified mutations in the PIK3CA gene in only two tumors that belong to G2. These two samples were closely associated in the non-supervised clustering analysis (HCC189 and HCC438, Figure 1). We identified 38 genes specifically over-expressed in the PIK3CA mutated samples when compared with the other tumors in groups G1 to G3. Among these genes, we validated the over-expression of two genes coding for the protein elongation factor EEF1A2 and the enterokinase PRSS7, specifically over-expressed in PIK3CA mutated tumors using QRT-PCR $(P=0.001$, Figure 4b) .

IGF2 over-expression in G1 and PIK3CA mutations in G2 were predicted to activate the AKT pathway. To test this hypothesis, we searched for a possible activation of the AKT pathway using western blotting in a series of 44 HCCs representing each of the transcriptomic groups. We found a specific over-expression of Insulin-like growth factor 1 receptor (IGF1R) in 7 of 9 G1 tumors in contrast to an IGF1R over-expression found in only $9 \%$ of the other groups $\left(P<10^{-4}\right.$, Figure 4c). We also identified a frequent overexpression of AKT in G1 (75\%) and G2 (25\%), compared to that found $(13 \%)$ in the other tumors. Moreover, phosphorylated AKT proteins were over-expressed in all tumors of G1 and in $58 \%$ of the G2 tumors in contrast to only $8 \%$ in the other groups demonstrating a frequent activation of AKT in G1 and G2 groups of tumors $\left(P<10^{-}\right.$

${ }^{3}$, Figure 4c). Accordingly, GSK3ß, a target of activated AKT, was found to be phosphorylated in $78 \%$ of G1 tumors, in $42 \%$ of G2 tumors and in only $9 \%$ of the other groups $\left(P<10^{-3}\right.$, Figure $\underline{4 c)}$.

c- HCCs in subgroup G3 over-expressed genes encoding proteins of the nuclear pore and controlling cell cycle

The HCC subgroup G3 mainly included tumors with TP53 mutation but without HBV infection. Significant associations were found with chromosome losses at 17p, 5q, 21q and 22q 
(Figure 3 and Table 1), and we frequently observed a high incidence of $C D K N 2 A$ promoter hypermethylation (data not shown). Examples of key genes specifically differentially expressed in G3 are provided in supplementary figure 1. We observed an over-expression of a large number of genes implicated in cell cycle control $(P<0.0003)$ including those encoding proteins that control cell cycle checkpoint (CDC6, MAD2L1, BUB1, TTK, SMC1L1), cyclins (CCNA2, $C C N E 2)$ and DNA replication checkpoint (MCM2, MCM3, MCM6, $A S K)$. Interestingly, genes encoding proteins implicated in nucleus import/export were also over-expressed including 6 proteins of the nuclear pore (KPNB1, RANBP5, XPO1, IPO7, NUP155, NUP107).

\section{d- G4 was a heterogeneous group of HCC tumors}

The G4 subgroup of samples was comprised of the 5 sample-pools of non-tumor liver tissues which clustered tightly together within a large, heterogeneous group containing 20 tumors (Figure 1). We also observed that 4 tumors, all having a TCF1 mutation, were closely associated in a small cluster of 5 tumors including the 3 hepatocellular adenomas and 2 well-differentiated HCCs. These results may suggest a possible continuum of early transcriptome alterations between non-tumor, benign and HCC tissue. We did not find other recurrent or unifying genetic and/or clinical characteristics in the remaining small clusters of G4 HCCs (Figure 1).

e- Activation of the Wnt pathway in G5 and G6 with under-expression of cell adhesion proteins in G6 related to satellite tumor nodules.

G5 and G6 HCCs were highly related to $\beta$-catenin activation $(70 \%$ and $100 \%$ of the tumors contained CTNNB1 mutations, respectively). No chromosome deletions specific to G5 and/or G6 were identified. In a search for possible $\beta$-catenin targeted genes we found a list of 83

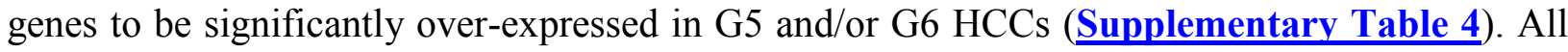
but two of these genes were also found significantly differentially expressed in a supervised test comparing ß-catenin mutated and non-mutated tumors. In addition to GPR49, GLUL and PAP/HIP three well known $\beta$-catenin target genes in the liver(18-20), we confirmed, using QRTPCR, the over-expression of 6 putative $\beta$-catenin target genes potentially implicated in tumorigenesis-(Figure 5a). We observed an even higher significant level of expression of all these putative B-catenin targeted genes in G6 compared to G5, even after exclusion of the samples without CTNNB1 mutation. We also found a higher over-expression of $\beta$-catenin in G6 tumors relative to the over-expression found in G5 tumors combined with a loss of signal at the 
plasma membrane and a strong localization in cytoplasm and nucleus (igure 5b) $)$. Consistent with this observation, we found an over-expression of $L E F 1$, a transcription factor that interacts with ß-catenin to activate Wnt-responsive target genes, in G6 tumors. In addition, we found an under-expression of $\mathrm{CDH1}$ (encoding E-cadherin) in the G6 subgroup (igure 5a) which may have accounted for the local invasion of these HCCs as shown by the quasi-constant presence of satellite nodules found around the principal tumor (Figure 3 and Table $\mathbf{1}$ ). We showed that the level of $C D H 1$ mRNA down-regulation was highly related to the down-regulated expression of the E-cadherin protein in G6 consistent with the high level of promoter methylation of CDH1 in these tumors (Figure 5c). Interestingly, in G5 related tumors, we observed an enrichment of under-expressed genes involved in response to biotic stimuli and immune response such as ARHGDIB, HLA-DPA1/B1, IFI16, IFI44, PTGER4, STAT1 and CLECSF2 $(P<0.003)$. Finally, combining transcriptome and immunohistochemical data, we found no evidence of a significant activation of the $\beta$-catenin pathway in $\mathrm{G} 1$ to G4 subgroups of HCCs. 


\section{$\underline{\text { Discussion }}$}

In order to elucidate the molecular diversity in HCC tumors without any a priori, we used non-supervised transcriptome wide approach to classify a large number of tumors that have been extensively clinically and genetically annotated. Using this approach, we obtained a robust classification of HCC which yielded 6 main subgroups reflecting the large spectrum of these tumors $(1,2,21)$. This classification was achieved using 16 diagnostic genes by QRT-PCR and was applied to an independent set of 63 tumors for a total of 120 HCCs studied. Our classification is in full agreement with previously published transcriptomic analyses of $\mathrm{HCC}(22-$ 24), which identified two tumor groups linked to chromosome stability/instability (corresponding to meta-groups 1 to 3 and 4 to 6). However, our study goes further by exquisitely refining this classification. Indeed the strength of our study resides in our inclusion of the vast amount of medical data namely: (1) our series of tumors surgically treated in France included the main different risk factors of HCC, i.e. HBV and HCV infections, alcohol abuse and heamochromatosis, as well as, (2) exhaustive number of clinical, histopathological and genetic annotations. Based on our study, we conclude that the primary clinical determinant of class membership is HBV infection whereas the other main determinants are genetic and epigenetic alterations including chromosome instability (FAL > 0.128), CTNNB1 and TP53 mutations and the parental imprinting (Figure 6).

The natural history of HCC has taught us that HBV related tumors (defining the G1 and G2 subgroups) were strikingly molecularly distinct from the other HCCs. Indeed tumors related to HCV infection and alcohol abuse are interspersed across subgroups G3 to G6. Our transcriptomic classification has enabled the identification of new entities of tumors. Subgroup G1 included HBV related tumors from younger patients (relative to the other HBV HCCs), frequently from Africa, with an equal sex ratio, low number of viral DNA copies, frequent AXIN1 mutations, absence of TP53 mutation and over-expression of genes normally imprinted (Figure 6). These results suggest that HBV infection early in life $(25,26)$ leads to a specific type of HCC demonstrating immature features with an abnormal parental gene imprinting selection possibly through the persistence of fetal hepatocytes or alternatively partial dedifferentiation of adult hepatocytes. These G1 tumors are related to the high-risk populations found in epidemiological studies(4, 27). Subgroup G6 has a 100\% incidence of CTNNB1 mutation, a high level of Wnt pathway activation (higher than in G5) and an inactivation of E-cadherin is 
consistent with the high invasive potential of these tumors as E-cadherin inactivation is known to participate in cell invasion process(28). Interestingly, AXIN1 mutated tumors segregated to different groups that were not characterized with harboring a CTNNB1 mutation suggesting that ß-catenin and Axin1 may operate by distinct ways to promote carcinogenesis. In human HCC, it appears that the inactivating mutations of the AXIN1 gene seems to differ strongly from the gain of function of $\beta$-catenin, as confirmed by in vitro experiments(17).

Apart from these large subgroups of tumors defined by frequent genetic alterations, our analysis has also defined homogeneous subgroups of tumors related to rare genetic alterations like TCF1 or PIK3CA mutations(29, 30). However, mutations specific to other small homogeneous subgroups of tumors have yet to be identified.

Thorgeirsson and collaborators defined a hepatoblast-like subtype of HCC that exhibited the most severe prognostic characteristics(31). Interestingly, our G1 tumor group shared the same characteristics as the hepatoblast-like type of HCC mentioned above. However, in our series of HCC, the most severe prognosis was related to G3 tumors that do not over-expressed fetal genes (supplementary figure 2). Previous reports have also identified the two main transcriptomic group classification as a relevant survival predictor(22). We found a better survival for group G4 to G6 when compare to G1 to G3, however, this difference did not reach statistical significance. These discrepancies may be related to the different distribution of risk factors in each tumor series. Furthermore, the unsupervised transcriptomic classification do not appear to be a robust survival determinant emphasizing the need to carefully consider the wide spectrum of epidemiological risk factors and genetic diversity of HCC when attempting to define a "universal" HCC survival predictors.

In conclusion, our global transcriptomic analysis has established a robust classification reflecting the natural diversity of human HCCs, the structural gene alterations and epigenetic deregulations accumulated during tumor progression. The high diversity of HCC tumor has clinical implications and our classification will help to further identify patients that will benefit from targeted therapies. 


\section{Acknowledgments:}

We warmly thank Jacqueline Godet, François Sigaux and Philippe Dessen managers of the Carte d'Identité des Tumeurs (CIT) program founded by the Ligue Nationale contre le Cancer; Daniela Geromin, Christelle Thibault, Patricia Legoix, Damien Gerald, Olivier Bluteau, for their experimental help; Fabien Petel for his help in the submission of the data to EBI; Philippe Bois for critical reading of the manuscript. We thank the technicians from the CEPH, Fondation Jean Dausset for their help in sequencing and all the clinicians that referred the patients. This work was supported by the Ligue Nationale Contre le Cancer and the Fondation de France. SB, SR

and EJ are supported by a Fondation de France, a Ligue Nationale Contre le Cancer and a Association pour la Recherche sur le Cancer grant fellowship, respectively. 
Figure 1: Unsupervised hierarchical clustering. The dendrogram in the upper panel was obtained based on the expression profile of 6,712 probe sets whose expression vary the most across samples from 57 HCC tumors, 3 hepatocellular adenomas and 5 pools of non-tumor tissues using Ward's linkage and 1-Pearson correlation coefficient. The different HCC subgroups (G1 to G6) are indicated in color. The heatmap on the lower shows the level of expression of 493 probe sets corresponding to a subselection of HCC subgroup specific genes (supplementary table 4). For each probe set, data were median centered (black), lowest and highest intensity values are in green and red, respectively.
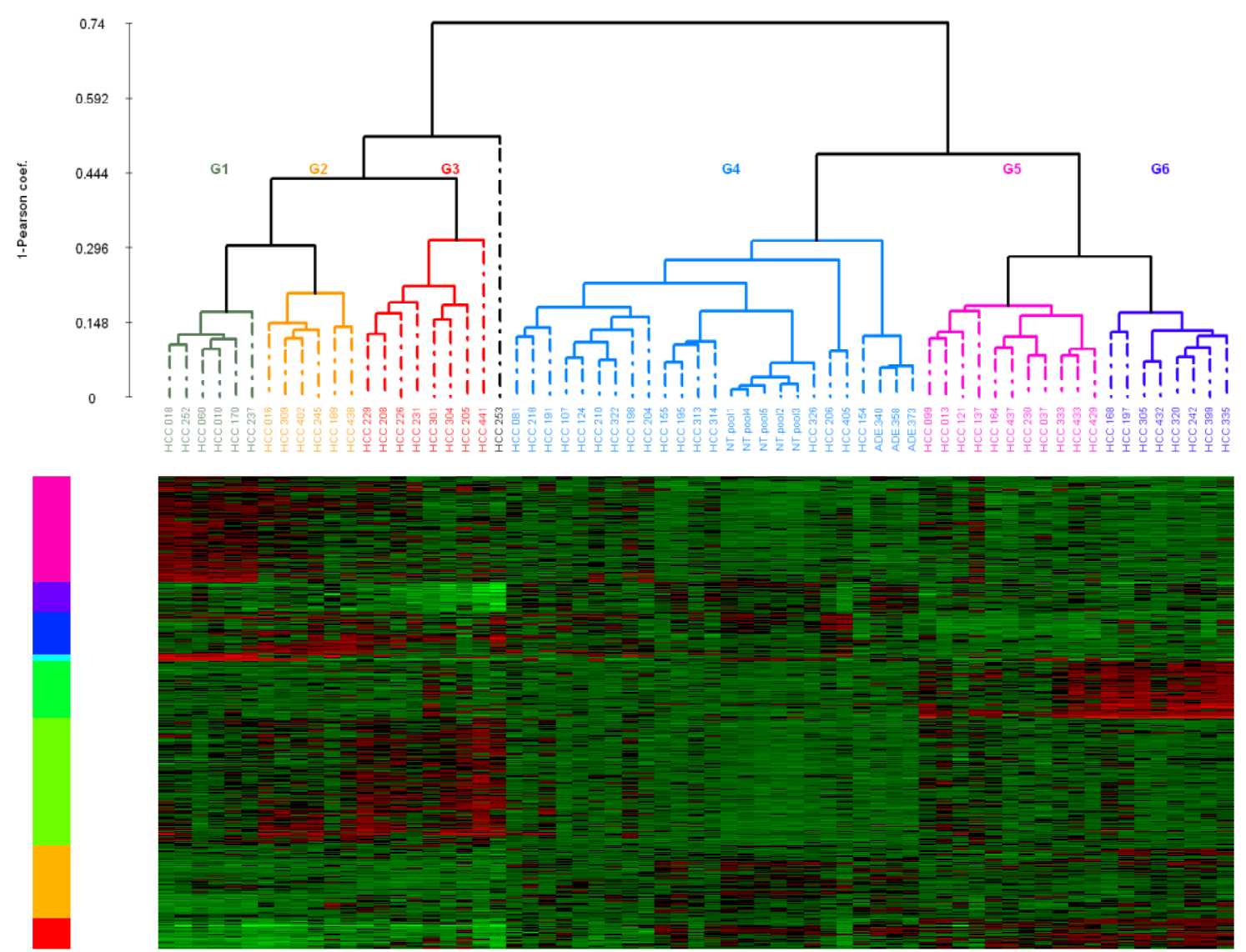
Table 1. Associations between transcriptomic groups, clinical, pathological and genetic variables.

\begin{tabular}{|c|c|c|c|c|}
\hline & Associated group & $\begin{array}{c}\text { Affymetrix } \\
\text { hybridizations } \\
(57 \text { HCC })\end{array}$ & $\begin{array}{c}\text { Validation set in } \\
\text { QRT-PCR } \\
\text { (63 HCC) }\end{array}$ & $\begin{array}{c}\text { Complete set } \\
(120 \text { HCC) }\end{array}$ \\
\hline \multicolumn{5}{|l|}{ Clinical characteristics } \\
\hline $\mathrm{AFP}>100 \mathrm{IU} / \mathrm{ml}$ & G1 & 0.01 & 0.006 & $10^{-4}$ \\
\hline Female & G1 & 0.06 & 0.05 & $<10^{-2}$ \\
\hline HBV low & G1 & $<10^{-4}$ & 0.04 & $10^{-5}$ \\
\hline HBV high & G2 & 0.05 & 0.07 & $<10^{-2}$ \\
\hline Age $<60 y$ & G1 and G2 & 0.04 & 0.09 & $<10^{-2}$ \\
\hline African origin & G1 & $<10^{-2}$ & 0.3 & $<10^{-2}$ \\
\hline Hemochromatosis & $\mathrm{G} 2$ & 1 & $<10^{-3}$ & 0.04 \\
\hline \multicolumn{5}{|c|}{ Pathological characteristics } \\
\hline Satellite nodules & G6 & $<10^{-2}$ & 0.3 & $<10^{-2}$ \\
\hline \multicolumn{5}{|l|}{ Genetic alterations } \\
\hline FAL $>0.128$ & $\mathrm{G} 1, \mathrm{G} 2$ and $\mathrm{G} 3$ & $<10^{-2}$ & $<10^{-3}$ & $<10^{-5}$ \\
\hline CTNNB1 mutations & G5 and G6 & $<10^{-10}$ & $<10^{-5}$ & $<10^{-15}$ \\
\hline TP53 mutations & $\mathrm{G} 2$ and $\mathrm{G} 3$ & 0.03 & 0.001 & $<10^{-3}$ \\
\hline AXIN1 mutation & G1 and G2 & 0.1 & $<10^{-2}$ & $<10^{-2}$ \\
\hline PIK3CA mutations & G2 & 0.01 & - & 0.01 \\
\hline CDH1 methylation & G5 and G6 & 0.01 & $<10^{-2}$ & $<10^{-2}$ \\
\hline LOH 17p & $\mathrm{G} 2$ and $\mathrm{G} 3$ & 0.005 & 0.02 & $<10^{-3}$ \\
\hline LOH 16p & G1, G2 and G3 & 0.005 & 0.05 & 0.0005 \\
\hline LOH 16q & G1 & 0.05 & 0.04 & $<10^{-2}$ \\
\hline LOH 4q & $\mathrm{G} 1, \mathrm{G} 2$ and $\mathrm{G} 3$ & 0.002 & 0.002 & $3.10^{-6}$ \\
\hline LOH 5q & $\mathrm{G} 3$ & 0.02 & 0.02 & $<10^{-3}$ \\
\hline LOH 13q & $\mathrm{G} 2$ & 0.02 & $<10^{-2}$ & $<10^{-3}$ \\
\hline LOH 21q & G3 & $<10^{-2}$ & 0.03 & $<10^{-3}$ \\
\hline LOH 22q & G3 & $<10^{-2}$ & 0.02 & $<10^{-3}$ \\
\hline
\end{tabular}

Shown are $P$ values obtained from Fisher exact tests based on the given genetic or clinical variable 
Figure 2: Predictor of the HCC classification using quantitative RT-PCR. a. Formula used for class-membership prediction. To classify a new sample, the $\Delta \mathrm{Ct}$ values (control: $18 \mathrm{~S}$ ) of the 16 genes used in formula are needed. Having calculated the distance between the given sample and the centroïd representation of each class, we affect the new sample to the closest class. $\mathbf{b}$. Parameters for each gene and for each class used in the formula are shown.

$\mathbf{a}$

Predicted class $\left(\right.$ sample $\left._{i}\right)=\underset{k=1 . .6}{\arg \min }\left(\right.$ Distance $_{\left.\left(\text {sample }_{i}, \text { class }_{k}\right)\right)}$
where : Distance $\left(\right.$ sample $_{i}$, class $\left._{k}\right)=\sum_{t=1 . .16} \frac{\left(\Delta \text { Ct }\left(\text { sample }_{i}, \text { gene }_{t}\right)-\mu\left(\text { class }_{k}, \text { gene }_{t}\right)\right)^{2}}{\sigma\left(\text { gene }_{t}\right)}$

b

\begin{tabular}{|c|l|l|l|l|l|l|l|}
\hline $\boldsymbol{\mu}$ & $\begin{array}{l}\text { class 1 } \\
(\mathrm{G} 1)\end{array}$ & $\begin{array}{l}\text { class 2 } \\
(\mathrm{G} 2)\end{array}$ & $\begin{array}{l}\text { class 3 } \\
(\mathrm{G} 3)\end{array}$ & $\begin{array}{l}\text { class 4 } \\
(\mathrm{G} 4)\end{array}$ & $\begin{array}{l}\text { class 5 } \\
(\mathrm{G} 5)\end{array}$ & $\begin{array}{l}\text { class 6 } \\
(\mathrm{G} 6)\end{array}$ & $\boldsymbol{\sigma}$ \\
\hline $\begin{array}{c}\text { gene 1 } \\
(R A B 1 A)\end{array}$ & -16.04 & -16.39 & -16.29 & -17.15 & -17.33 & -16.95 & 0.23 \\
\hline $\begin{array}{c}\text { gene 2 } \\
(P A P)\end{array}$ & -27.02 & -28.75 & -23.48 & -27.87 & -19.23 & -11.33 & 16.63 \\
\hline $\begin{array}{c}\text { gene 3 } \\
(N R A S)\end{array}$ & -17.41 & -16.92 & -16.25 & -17.31 & -16.96 & -17.26 & 0.27 \\
\hline $\begin{array}{c}\text { gene 4 } \\
(R A M P 3)\end{array}$ & -23.12 & -23.54 & -25.34 & -22.36 & -23.09 & -23.06 & 1.23 \\
\hline $\begin{array}{c}\text { gene 5 } \\
(M E R T K)\end{array}$ & -18.43 & -18.72 & -21.24 & -18.29 & -17.03 & -16.16 & 7.23 \\
\hline $\begin{array}{c}\text { gene 6 } \\
(P I R)\end{array}$ & -19.81 & -18.44 & -16.73 & -18.28 & -17.09 & -17.25 & 0.48 \\
\hline $\begin{array}{c}\text { gene 7 } \\
(\mathrm{EPHA})\end{array}$ & -16.51 & -16.68 & -19.89 & -17.04 & -18.70 & -21.98 & 1.57 \\
\hline $\begin{array}{c}\text { gene 8 } \\
(L A M A 3)\end{array}$ & -20.44 & -20.58 & -20.19 & -21.99 & -18.77 & -16.85 & 2.55 \\
\hline $\begin{array}{c}\text { gene 9 } \\
(G 0 S 2)\end{array}$ & -17.45 & -14.82 & -18.18 & -14.78 & -17.99 & -16.06 & 3.88 \\
\hline $\begin{array}{c}\text { gene 10 } \\
(H N 1)\end{array}$ & -17.16 & -16.92 & -15.91 & -17.88 & -17.72 & -17.93 & 0.54 \\
\hline $\begin{array}{c}\text { gene 11 } \\
(P A K 2)\end{array}$ & -16.56 & -17.86 & -16.99 & -18.14 & -17.92 & -17.97 & 0.58 \\
\hline $\begin{array}{c}\text { gene 12 } \\
(A F P)\end{array}$ & -12.36 & -16.68 & -26.80 & -27.28 & -25.97 & -23.47 & 14.80 \\
\hline $\begin{array}{c}\text { gene 13 } \\
(C Y P 2 C 9)\end{array}$ & -16.99 & -18.27 & -16.26 & -16.23 & -13.27 & -14.44 & 5.47 \\
\hline $\begin{array}{c}\text { gene 14 } \\
(C D H 2)\end{array}$ & -14.76 & -15.20 & -18.91 & -15.60 & -15.48 & -17.32 & 10.59 \\
\hline $\begin{array}{c}\text { gene 15 } \\
(H A M P)\end{array}$ & -20.19 & -19.53 & -21.32 & -18.51 & -25.06 & -26.10 & 13.08 \\
\hline $\begin{array}{c}\text { gene 16 } \\
(S A E 1)\end{array}$ & -17.10 & -17.37 & -16.79 & -18.22 & -17.72 & -18.16 & 0.31 \\
\hline
\end{tabular}


Figure 3: Clinical and genetic annotations for the classification of the whole of $120 \mathrm{HCC}$. Samples (in columns) are ordered by group G1 to G6, sample names are in grey (56 Affymetrix classified samples), red (one HCC misclassified by QRT-PCR) or black (independent series of 63 HCC). Features are indicated in black and white boxes when positive and negative. FAL indicates Fractional Allelic Loss, in black tumors deleting more than 5 chromosome arms; Mut, mutation; sat. nodules, satellite nodules at less than $1 \mathrm{~cm}$ from the principal tumor; AFP, Alphafetoprotein.

\begin{tabular}{|c|c|c|c|c|c|c|c|}
\hline & & 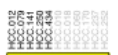 & 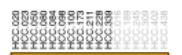 & 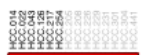 & 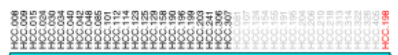 & 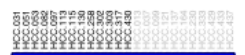 & 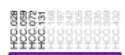 \\
\hline roup & & G1 & $\mathrm{G} 2$ & & G4 & G5 & G6 \\
\hline TNNE & & س11110 & IIIIII & & 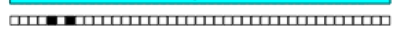 & & \\
\hline$A L>$ & & & n & & 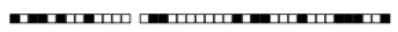 & & \\
\hline $\mathrm{bH}$ & & שسחس & 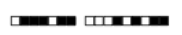 & & |س & 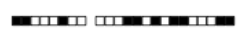 & I \\
\hline 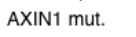 & & $=110$ & שسח & مس & 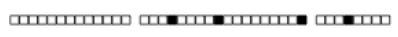 & س & 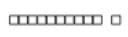 \\
\hline DH & & 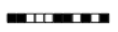 & |ח & m & 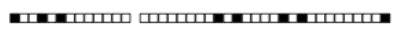 & טسח & Ш \\
\hline BV & & سחسم & 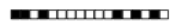 & سחسחس & 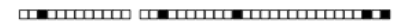 & 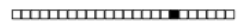 & 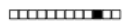 \\
\hline$F P>$ & & & 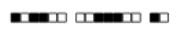 & שח & | & م=10m & m.1. \\
\hline at. & & एक & |س & III) & 110 & 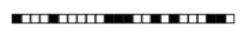 & $=$ \\
\hline$m$ & & 10 & تستس & مس سمب & 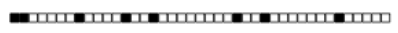 & 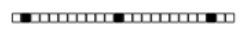 & 山 \\
\hline oung & & Deras & & -1 & 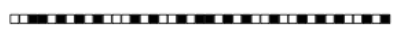 & 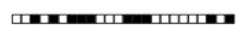 & $=$ \\
\hline & & 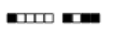 & (10س & مسח & 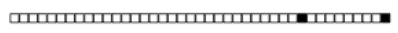 & w & \\
\hline
\end{tabular}


Figure 4: Validation of selected genes and proteins specific of HCC subgroup G1 and G2. a. Validation of AFP, IGF2, SOX9, PEG3, MYH4 and H19 gene expression using QRT-PCR. Boxplots (from $25^{\text {th }}$ percentile to the $75^{\text {th }}$ percentile with a line at the median) show the range of relative expression (tumor versus the mean of 21 non-tumor (T/NT)) in the predicted subgroups G1 (n=10) and G2 to G6 (n=99), 21 non-tumor samples (NT) and 19 fetal liver samples (FL). The whiskers extend above and below the box to show the first and the $9^{\text {th }}$ decile. $P$ values from Kruskal-Wallis test are indicated. b. Validation of EEF1A2 and PRSS7 genes over-expressed in PIK3CA mutated tumors compared to 107 non-mutated HCC. $P$ values from a $t$-test are shown. c. Protein expression analysis of Akt, phosphoAkt (Ser473), PhosphoGSK3ß (Ser9) and IGF1R was performed using western blotting in $44 \mathrm{HCC}$ distributed in all transcriptomic subgroups. Graphs represent in G1, G2 and G3 to G6 subgroups the percentage of tumors that over-express these proteins when compared to non-tumor tissues. Panel on the right illustrates protein expression profiles obtained in the different HCC subgroups.

$\mathbf{a}$
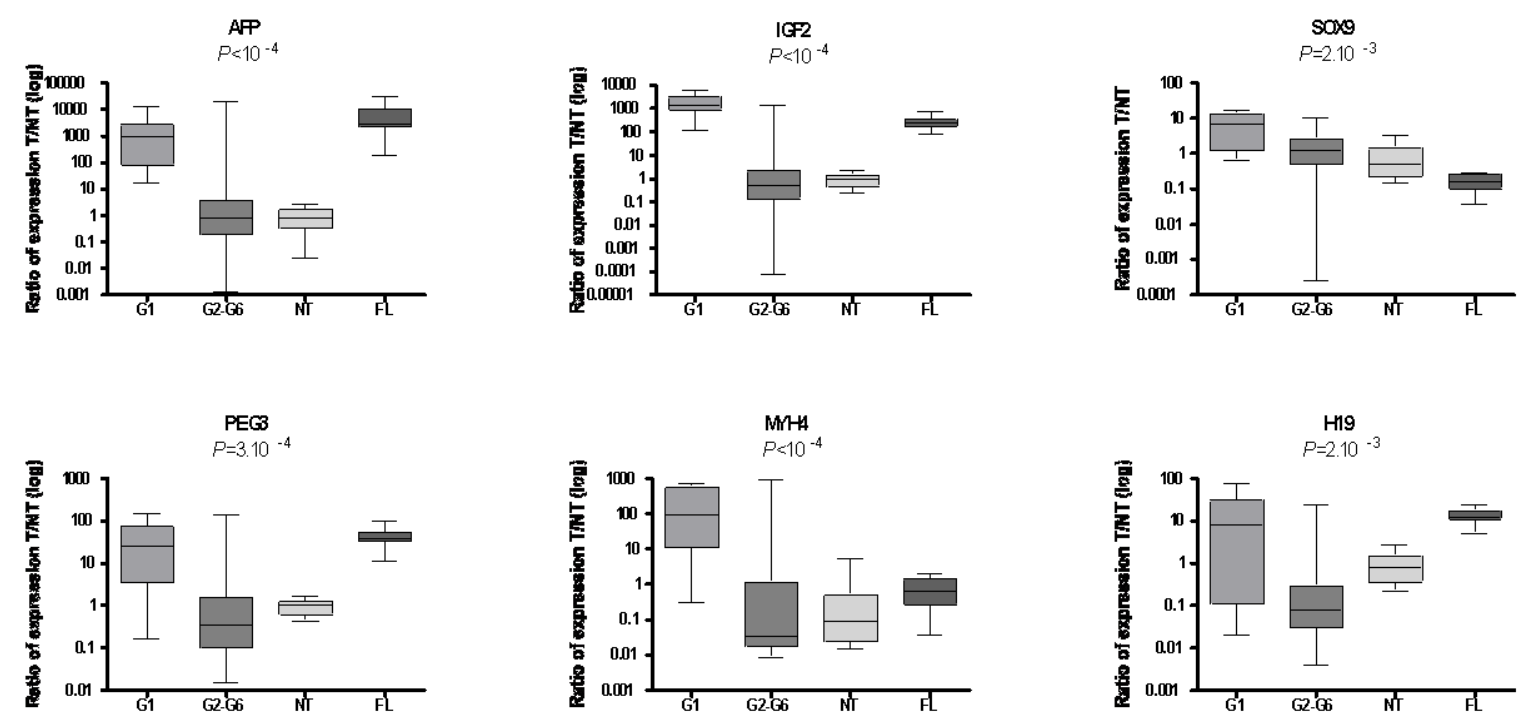

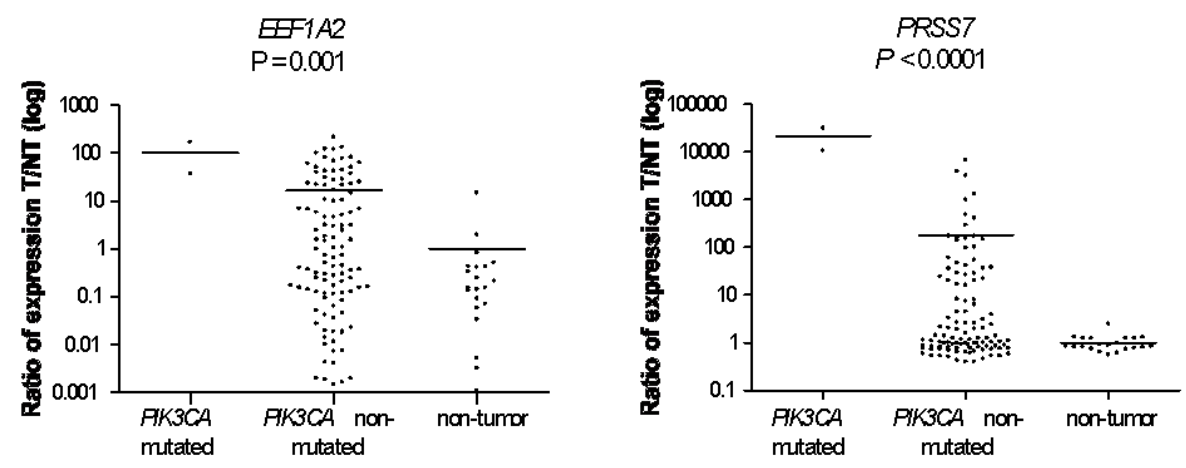

c
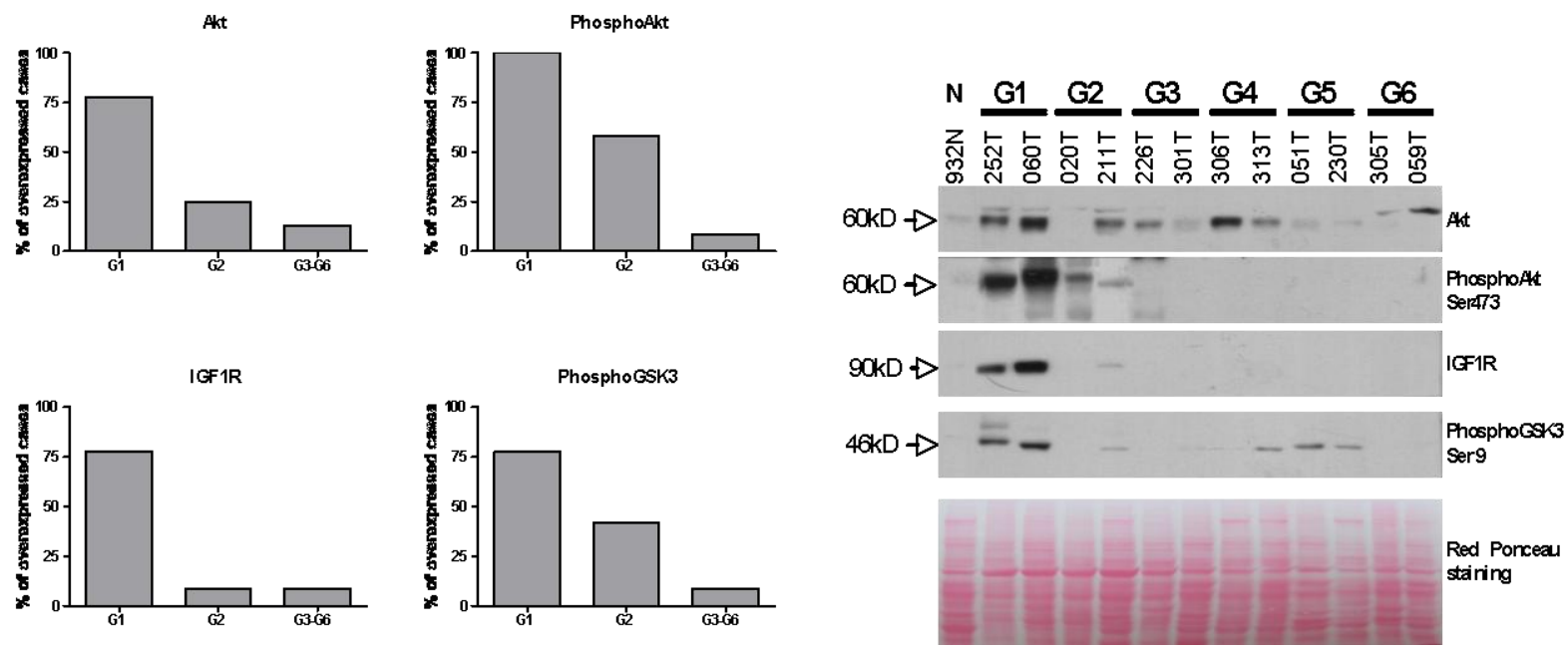
Figure 5: Characterization of HCC tumors leading to G5 and G6 subgroups. a. Validation of genes using QRT-PCR. Relative expression (tumor versus mean of non-tumor (T/NT)) for GLUL, SPARCL1, TBX3, LAMA3, MERTK, EPHB2, PAP, LEF1 and CDH1 were analyzed in tumors related to G1-G4 (n=75), G5 $(\mathrm{n}=23), \mathrm{G} 6(\mathrm{n}=11)$ and non-tumor samples $(\mathrm{n}=21)$. $P$ values from Kruskal-Wallis test are indicated. b. ß-catenin immunostaining in representative cases of HCC mutated for B-catenin and leading to G5 and G6. In case HCC303 (G5), note a low number of stained nuclei and an intense staining of the plasma membrane (white arrows). In case HCC305 (G6), cytoplasm and nuclei of hepatocytes are intensively stained (black arrows) without signal at the plasma membrane. c. Protein expression of E-cadherin using western blotting (upper panels) and mRNA level of expression using QRT-PCR (lower panel) in HCC of group G5 and G6.

a
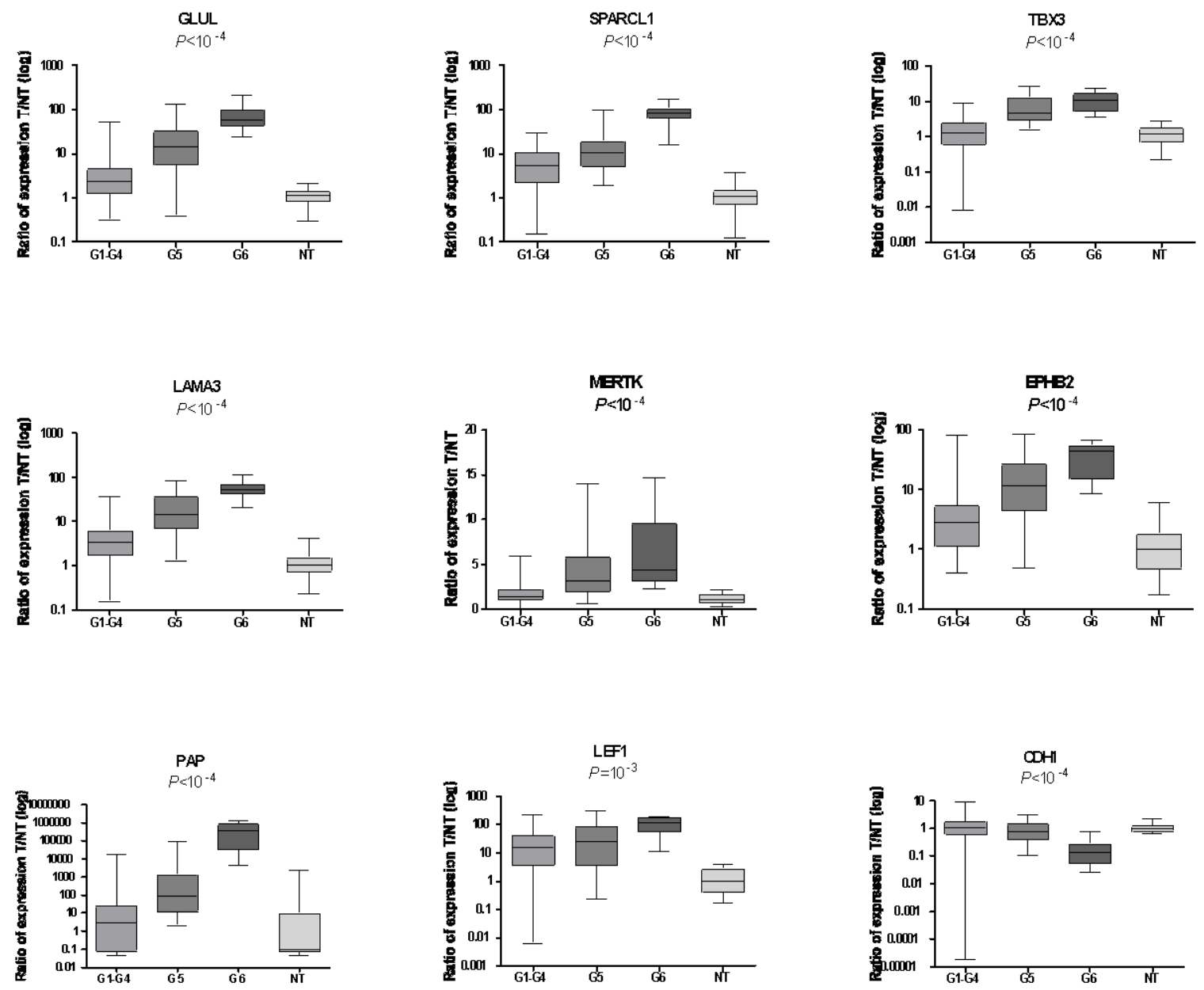
b

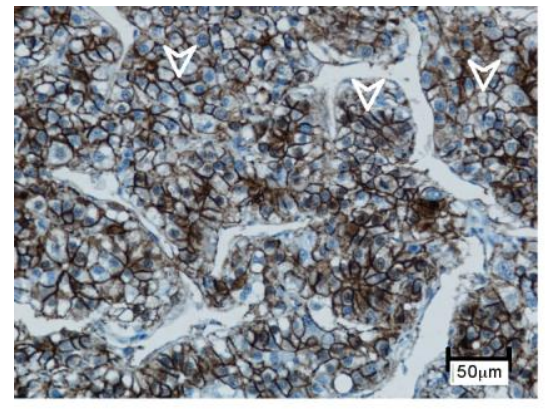

HCC 303 G5

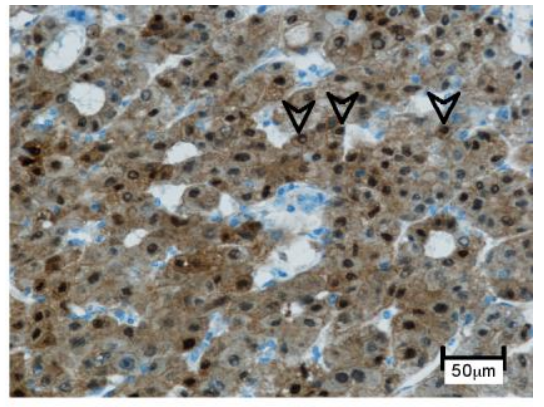

HCC 305 G6

c

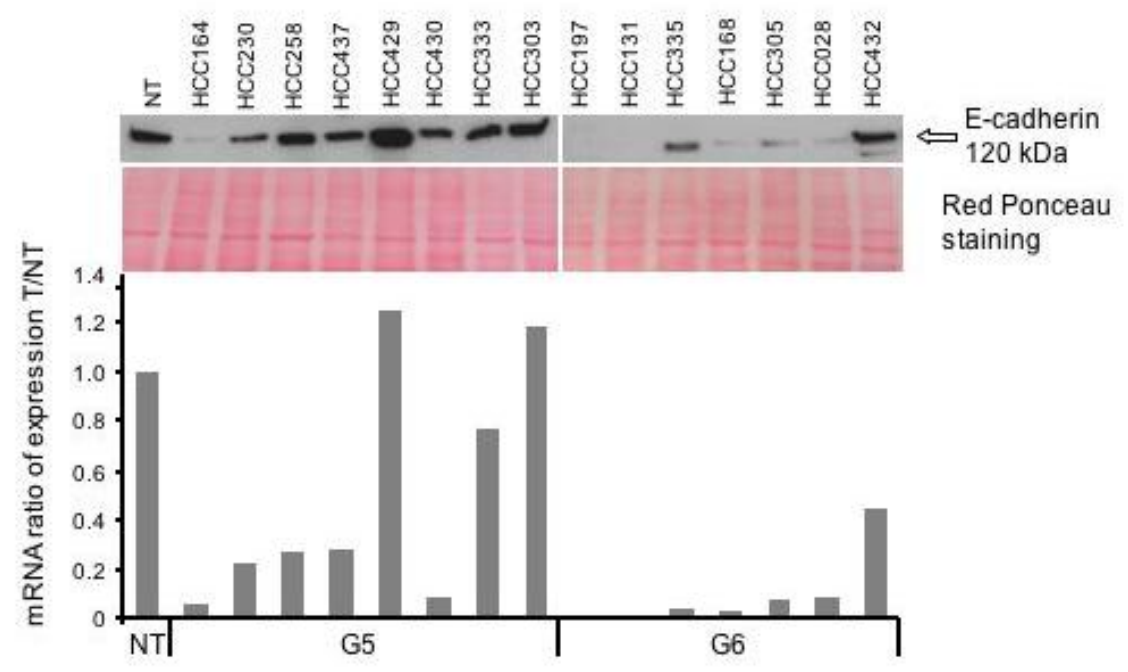


Figure 6: Schematization of the different HCC subgroups defined by transcriptome analysis with their related clinical, genetic and pathways. G1 to G6 indicates the HCC subgroups of tumors defined by transcriptome analysis. Vertical lines indicate significant associated features (see table 1, figure 3 and supplementary Table 5). LOH, loss of heterozygosity; Hemochrom, haemochromatosis; AFP, alpha-fetoprotein, HBV, hepatitis B virus. Red and green indicates primarily over- and under-expressed genes in that particular functional category, respectively. *asterisk indicates rare feature.

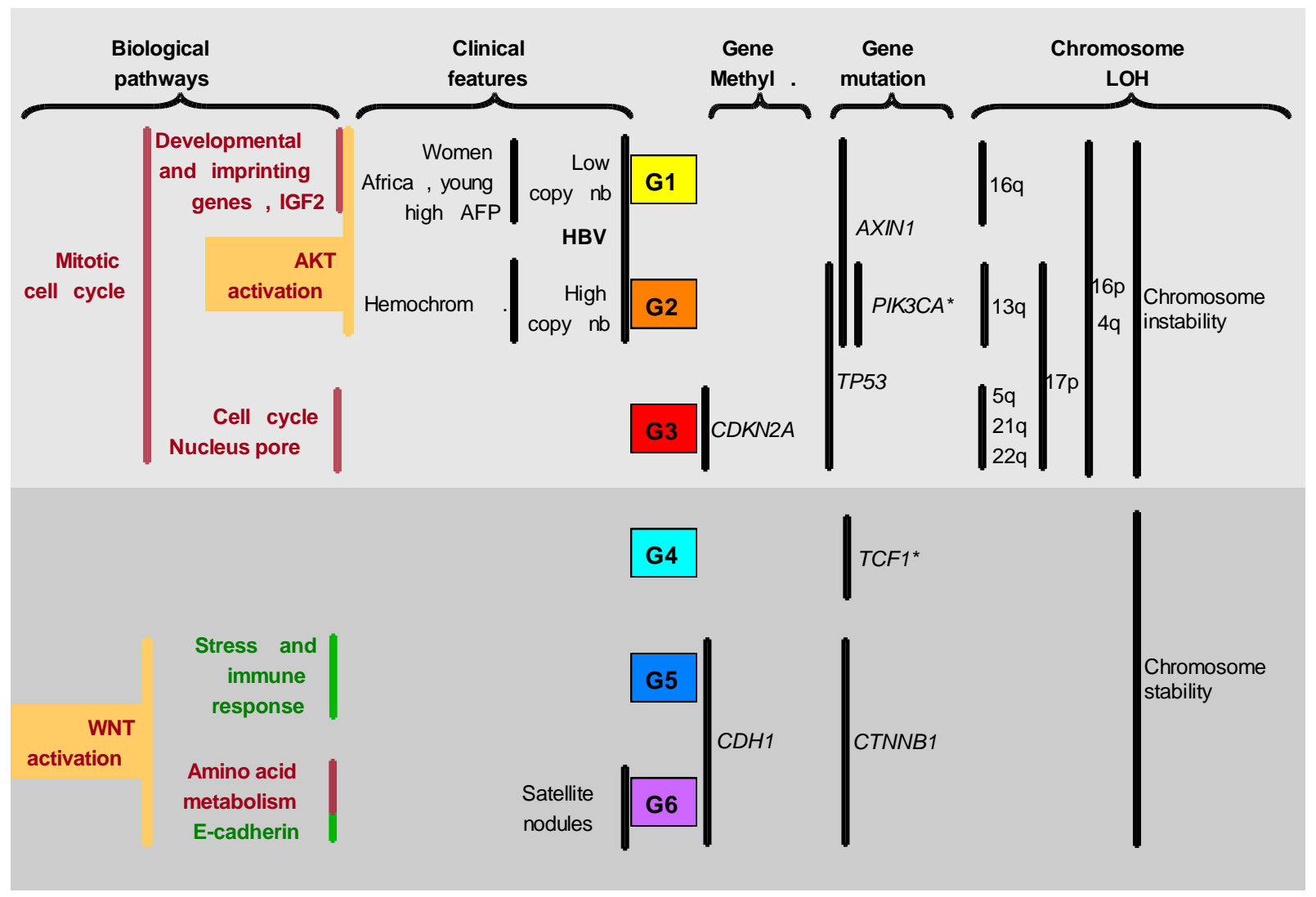




\section{References}

1. Bosch FX, Ribes J, Borras J. Epidemiology of primary liver cancer. Semin Liver Dis 1999; 19:271-285.

2. Edmondson HA, Peters RL. Tumors of the liver: pathologic features. Semin Roentgenol $1983 ; 18: 75-83$.

3. Thorgeirsson SS, Grisham JW. Molecular pathogenesis of human hepatocellular carcinoma. Nat Genet 2002;31:339-346.

4. Brechot C. Pathogenesis of hepatitis B virus-related hepatocellular carcinoma: old and new paradigms. Gastroenterology 2004;127:S56-61.

5. Laurent-Puig P, Zucman-Rossi J. Genetics of hepatocellular tumors. Oncogene 2006;25:3778-3786.

6. Bressac B, Galvin KM, Liang TJ, Isselbacher KJ, Wands JR, Ozturk M. Abnormal structure and expression of p53 gene in human hepatocellular carcinoma. Proc Natl Acad Sci U S A 1990;87:1973-1977.

7. de La Coste A, Romagnolo B, Billuart P, Renard CA, Buendia MA, Soubrane O, Fabre $\mathrm{M}$, et al. Somatic mutations of the beta-catenin gene are frequent in mouse and human hepatocellular carcinomas. Proc Natl Acad Sci U S A 1998;95:8847-8851.

8. Miyoshi Y, Iwao K, Nagasawa Y, Aihara T, Sasaki Y, Imaoka S, Murata M, et al. Activation of the beta-catenin gene in primary hepatocellular carcinomas by somatic alterations involving exon 3. Cancer Res 1998;58:2524-2527.

9. Satoh S, Daigo Y, Furukawa Y, Kato T, Miwa N, Nishiwaki T, Kawasoe T, et al. AXIN1 mutations in hepatocellular carcinomas, and growth suppression in cancer cells by virusmediated transfer of AXIN1. Nat Genet 2000;24:245-250.

10. Roncalli M, Bianchi P, Bruni B, Laghi L, Destro A, Di Gioia S, Gennari L, et al. Methylation framework of cell cycle gene inhibitors in cirrhosis and associated hepatocellular carcinoma. Hepatology 2002;36:427-432.

11. Azechi H, Nishida N, Fukuda Y, Nishimura T, Minata M, Katsuma H, Kuno M, et al. Disruption of the $\mathrm{p} 16 /$ cyclin D1/retinoblastoma protein pathway in the majority of human hepatocellular carcinomas. Oncology 2001;60:346-354.

12. De Souza AT, Hankins GR, Washington MK, Orton TC, Jirtle RL. M6P/IGF2R gene is mutated in human hepatocellular carcinomas with loss of heterozygosity. Nat Genet 1995;11:447-449.

13. Su TS, Liu WY, Han SH, Jansen M, Yang-Fen TL, P'Eng F K, Chou CK. Transcripts of the insulin-like growth factors I and II in human hepatoma. Cancer Res 1989;49:1773-1777.

14. Laurent-Puig P, Legoix P, Bluteau O, Belghiti J, Franco D, Binot F, Monges G, et al. Genetic alterations associated with hepatocellular carcinomas define distinct pathways of hepatocarcinogenesis. Gastroenterology 2001;120:1763-1773.

15. Lee S, Lee HJ, Kim JH, Lee HS, Jang JJ, Kang GH. Aberrant CpG island hypermethylation along multistep hepatocarcinogenesis. Am J Pathol 2003;163:1371-1378.

16. Zochbauer-Muller S, Fong KM, Virmani AK, Geradts J, Gazdar AF, Minna JD. Aberrant promoter methylation of multiple genes in non-small cell lung cancers. Cancer Res 2001;61:249255.

17. Zucman-Rossi J, Benhamouche S, Godard C, Boyault S, Grimber G, Balabaud C, Sa Cunha A, et al. Differential effects of inactivated Axin1 and activated B-catenin mutations in human hepatocellular carcinomas. Oncogene 2006; In press. 
18. Cadoret A, Ovejero C, Terris B, Souil E, Levy L, Lamers WH, Kitajewski J, et al. New targets of beta-catenin signaling in the liver are involved in the glutamine metabolism. Oncogene 2002;21:8293-8301.

19. Yamamoto Y, Sakamoto M, Fujii G, Tsuiji H, Kenetaka K, Asaka M, Hirohashi S. Overexpression of orphan G-protein-coupled receptor, Gpr49, in human hepatocellular carcinomas with beta-catenin mutations. Hepatology 2003;37:528-533.

20. Cavard C, Terris B, Grimber G, Christa L, Audard V, Radenen-Bussiere B, Simon MT, et al. Overexpression of regenerating islet-derived 1 alpha and 3 alpha genes in human primary liver tumors with beta-catenin mutations. Oncogene 2006;25:599-608.

21. Bosch FX, Ribes J, Diaz M, Cleries R. Primary liver cancer: worldwide incidence and trends. Gastroenterology 2004;127:S5-S16.

22. Lee JS, Chu IS, Heo J, Calvisi DF, Sun Z, Roskams T, Durnez A, et al. Classification and prediction of survival in hepatocellular carcinoma by gene expression profiling. Hepatology 2004;40:667-676.

23. Breuhahn K, Vreden S, Haddad R, Beckebaum S, Stippel D, Flemming P, Nussbaum T, et al. Molecular profiling of human hepatocellular carcinoma defines mutually exclusive interferon regulation and insulin-like growth factor II overexpression. Cancer Res 2004;64:60586064.

24. Chen X, Cheung ST, So S, Fan ST, Barry C, Higgins J, Lai KM, et al. Gene expression patterns in human liver cancers. Mol Biol Cell 2002;13:1929-1939.

25. Davis LG, Weber DJ, Lemon SM. Horizontal transmission of hepatitis B virus. Lancet 1989; 1:889-893.

26. Wong VC, Lee AK, Ip HM. Transmission of hepatitis B antigens from symptom free carrier mothers to the fetus and the infant. Br J Obstet Gynaecol 1980;87:958-965.

27. Yu MC, Yuan JM. Environmental factors and risk for hepatocellular carcinoma. Gastroenterology 2004;127:S72-78.

28. Behrens J, Mareel MM, Van Roy FM, Birchmeier W. Dissecting tumor cell invasion: epithelial cells acquire invasive properties after the loss of uvomorulin-mediated cell-cell adhesion. J Cell Biol 1989;108:2435-2447.

29. Bluteau O, Jeannot E, Bioulac-Sage P, Marques JM, Blanc JF, Bui H, Beaudoin JC, et al. Bi-allelic inactivation of TCF1 in hepatic adenomas. Nat Genet 2002;32:312-315.

30. Lee JW, Soung YH, Kim SY, Lee HW, Park WS, Nam SW, Kim SH, et al. PIK3CA gene is frequently mutated in breast carcinomas and hepatocellular carcinomas. Oncogene 2005;24:1477-1480.

31. Lee JS, Heo J, Libbrecht L, Chu IS, Kaposi-Novak P, Calvisi DF, Mikaelyan A, et al. A novel prognostic subtype of human hepatocellular carcinoma derived from hepatic progenitor cells. Nat Med 2006;12:410-416. 